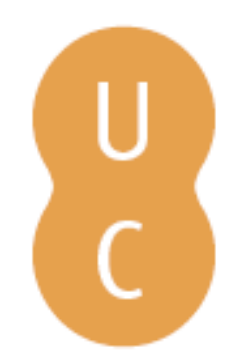

\title{
nommalina
}

\section{A cultura açucareira e a alimentação: património linguístico e cultural comum das ilhas atlânticas e do Brasil}

\author{
Autor(es): $\quad$ Nunes, Naidea Nunes \\ Publicado por: Imprensa da Universidade de Coimbra; Annablume \\ URL \\ persistente: URI:http://hdl.handle.net/10316.2/39620 \\ DOI: $\quad$ DOI:https://doi.org/10.14195/978-989-26-1191-4_11 \\ Accessed : $\quad$ 26-Apr-2023 09:22:12
}

A navegação consulta e descarregamento dos títulos inseridos nas Bibliotecas Digitais UC Digitalis, UC Pombalina e UC Impactum, pressupõem a aceitação plena e sem reservas dos Termos e Condições de Uso destas Bibliotecas Digitais, disponíveis em https://digitalis.uc.pt/pt-pt/termos.

Conforme exposto nos referidos Termos e Condições de Uso, o descarregamento de títulos de acesso restrito requer uma licença válida de autorização devendo o utilizador aceder ao(s) documento(s) a partir de um endereço de IP da instituição detentora da supramencionada licença.

Ao utilizador é apenas permitido o descarregamento para uso pessoal, pelo que o emprego do(s) título(s) descarregado(s) para outro fim, designadamente comercial, carece de autorização do respetivo autor ou editor da obra.

Na medida em que todas as obras da UC Digitalis se encontram protegidas pelo Código do Direito de Autor e Direitos Conexos e demais legislação aplicável, toda a cópia, parcial ou total, deste documento, nos casos em que é legalmente admitida, deverá conter ou fazer-se acompanhar por este aviso.

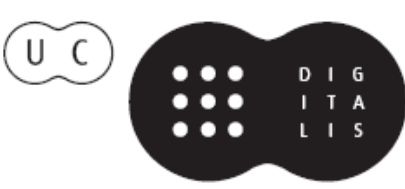




\title{
A cultura açucareira e a alimentação: \\ PATRIMÓNIO LINGUÍSTICO E CULTURAL COMUM \\ DAS ILHAS ATLÂNTICAS E do BRASIL \\ The sugar culture and food: common linguistic and cultural heritage of the Atlantic Islands and Brazil
}

\author{
Naidea Nunes Nunes \\ Universidade da Madeira \\ naidea@uma.pt \\ Cada coisa no seu tempo \\ No seu tempo lembra tudo \\ Bolos doces pela Festa \\ Malassadas no Entrudo \\ (quadra popular da Madeira)
}

Resumo: A alimentação como património cultural e identitário comum ao espaço atlântico é um tema fulcral para compreendermos as relações históricas existentes entre as ilhas atlânticas e entre a Madeira e o Brasil. A realização de inquéritos linguístico-etnográficos nestes espaços permite-nos conhecer a realidade alimentar atual, nomeadamente no que diz respeito aos doces e bebidas associados à cultura açucareira. Mostra-nos a importância dos estudos interdisciplinares, sobretudo da História, da Etnografia e da Sociologia, para compreendermos melhor a circulação e transmissão das coisas e palavras da alimentação entre os dois lados do Atlântico, contribuindo para o conhecimento do património alimentar da lusofonia, como herança linguística e cultural.

Palavras-chave: Cultura Açucareira, Alimentação, Património Linguístico e Cultural.

Aвstract: Food as cultural and characteristic heritage common to the Atlantic space is a core theme for the understanding of the historical relationships between the Atlantic islands and between Madeira and Brazil. The implementation of linguistic and ethnographic enquiries in these areas allow us to learn about current food habits, concerning sweets and drinks related to the sugar culture. It shows us the importance of interdisciplinary studies, mainly in History, Ethnography and Sociology, so as to better understand the flow and transmission of the things and words on food on both sides of the Atlantic, contributing to the knowledge of the Lusophone food heritage as linguistic and cultural heritage.

KEY-Words: Sugar Culture, Food Heritage, Linguistic and Cultural Heritage. 
A alimentação como património linguístico e cultural comum das ilhas atlânticas e do Brasil é um tema fulcral para compreendermos as relações históricas existentes entre os dois lados do Attântico. A realização de inquéritos linguístico-etnográficos sobre a cultura açucareira nestes espaços permite-nos conhecer a realidade atual, nomeadamente no que diz respeito aos doces e bebidas, que revelam a transmissão e circulação de sabores e saberes entre estas áreas geográficas.

Depois do trabalho de investigação diacrónico sobre a cultura açucareira do Mediterrâneo ao Atlântico (através do estudo da documentação histórica), tendo como epicentro a ilha da Madeira no desenvolvimento e difusão da terminologia e das técnicas açucareiras nas Canárias, Cabo Verde, S. Tomé e Príncipe e Brasil, iniciámos o estudo sincrónico (através da realização de inquéritos linguístico-etnográficos a agricultores e trabalhadores de engenhos), para recolher a terminologia atual da produção açucareira, nomeadamente do cultivo e colheita da cana-de-açúcar, da moenda da cana e do fabrico de mel, açúcar, rapadura, alfenim e aguardente, bem como a recolha de tradições de doces e bebidas da cultura açucareira, como património linguístico e cultural atlântico. Além das entrevistas realizadas na ilha da Madeira, deslocámo-nos às Canárias, a Cabo Verde, a S. Tomé e Príncipe e ao Brasil para aplicar o mesmo questionário, com as devidas adaptações às diferentes realidades geográficas, socioeconómicas e culturais, recolhendo e salvaguardando o vocabulário desta área de atividade artesanal e tradicional em vias de extinção.

A partir das Canárias, os termos da cultura açucareira madeirense foram levados para toda a América espanhola, onde foi implementada a produção açucareira e onde ainda hoje são conservados, como é o caso da Venezuela e da Colômbia. Referimos estes dois países em particular porque tivemos a oportunidade de coordenar um projeto internacional sobre a terminologia açucareira ibero-americana com dois investigadores de universidades destes países, comprovando a continuidade destes termos açucareiros. $\mathrm{Na}$ nossa deslocação ao Brasil, para recolher o património linguístico da cultura açucareira, percorremos o litoral do país (do Norte ao Sul), desde o Estado da Paraíba, Pernambuco, Baía, Minas Gerais, Santa Catarina até o Estado do Rio Grande do Sul. A produção açucareira desenvolveu-se de tal maneira no Brasil que a maior parte da população brasileira e mesmo portuguesa pensa que é natural deste país, esquecendo que foi transplantada da ilha da Madeira pelos mestres de engenho e mestres de açúcar madeirenses. Deste modo, muitos dos termos da cultura açucareira registados nos dicionários, nomeadamente de Morais Silva, como brasileirismos, surgem primeiramente na documentação histórica da Madeira. O estudo desta documentação, com referências à produção açucareira madeirense, mostra-nos que os termos: trapiche, açúcar mascavo, rapadura e açúcar de panela, entre outros, já ocorrem 
na Madeira em finais do século XV, inícios do século XVI, antecipando a sua primeira atestação na Língua Portuguesa.

As relações históricas e económicas entre as ilhas atlânticas (Açores, Madeira, Canárias, Cabo Verde e S. Tomé e Príncipe) e o Brasil explicam a existência de trocas culturais e, por via disso, de um património linguístico e cultural comum. Este diálogo de línguas e culturas realizou-se através da mobilidade de pessoas, coisas e palavras (plantas, animais, técnicas, objetos e produtos), iniciada pelos portugueses enquanto pioneiros na expansão ultramarina. A propósito da alimentação, Cardoso escreve:

(...) ao querer confrontar a gastronomia dos outros arquipélagos que constituem a Macaronésia - Açores, Canárias, para além de Cabo Verde -, conclui através dos comeres e beberes, da linguagem usada, e de alguns ingredientes a existência de hábitos gastronómicos e culinários tão similares, ficando bem claro que os primeiros povoadores traziam e levavam os seus produtos através do Atlântico, trocavam e aproveitavam o que tinham, o que a Natureza lhes oferecia, ficando essas marcas bem vincadas num aspeto fundamental da vida dos povos - que é a Alimentação. ${ }^{1}$

A grande ligação entre as ilhas atlânticas surge a partir da cultura açucareira. Pois, mesmo em relação aos Açores, não podemos esquecer que houve um breve cultivo de cana-de-açúcar, levado a partir da ilha da Madeira, tal como aconteceu nas Canárias. Gaspar Frutuoso, em Saudades da Terra, testemunha o seu cultivo pelo menos até meados do século $\mathrm{XVI}^{2}$. Sabemos que houve intercâmbio de mestres açucareiros entre os três arquipélagos, Madeira, Açores e Canárias, sendo natural que as técnicas e as palavras fossem as mesmas. Desenvolveram-se as mesmas indústrias derivadas, a conserva de frutas e os confeitos. Merece especial destaque o alfenim, doce de origem árabe muito antigo, atestado na documentação histórica da Madeira, em 1469: alfinij (do árabe al-fenid, 'alvo, branco'), oriundo do Mediterrâneo (da Sicília e de Valência), onde os árabes foram responsáveis pelo grande desenvolvimento da indústria açucareira e da farmacopeia.

A partir da segunda metade do século XV, ocorreu um grande desenvolvimento da produção açucareira na Madeira e, consequentemente, também da elaboração de confeitos e conservas de fruta. A indústria conserveira foi muito importante na ilha da Madeira, tal como se deduz de um documento de 1469: "mulheres de boas pessoas e muitos pobres que lavraram os açucares baixos em tantas maneiras de conservas e alfenim e confeitos de que têm grandes proveitos que dão remédio a suas vidas e dão grande nome a terra nas

\footnotetext{
${ }^{1}$ Cardoso 1994: 13.

${ }^{2}$ Frutuoso 1977-1987, livro IV, vol. II: 100.
} 
partes onde vão (...)”. ${ }^{3}$ A fama da arte da confeitaria madeirense espalhou-se por toda a Europa e teve o expoente máximo na embaixada enviada por Simão Gonçalves da Câmara ao Papa Leão X, em 1579, que levou conservas e alfenim. Segundo Gaspar Frutuoso, em Saudades da Terra, foram "muitos mimos e brincos da ilha de conservas, e o sacro palácio todo feito de açúcar, e os cardiais todos feitos de alfenim" ". O açúcar da Madeira está também bem presente em $O$ livro de cozinha de um frade português do século $X V I^{5}$, editado por Barros (2013), por exemplo, na confeção de filhoses e do cuscuz, com receitas muito informativas.

No que se refere ao alfenim, terá permanecido como figuras de açúcar branco na decoração de bolos de noiva, ou seja, continua a ser utilizado nas esculturas de açúcar para decoração de mesas festivas. Sainz-Trueva refere "bolos de família guarnecidos de alfenim". Nos Açores, o alfenim é um doce típico ou tradicional da ilha Terceira, utilizado em oferendas e promessas nas Festas do Divino Espírito Santo. Trata-se de uma massa feita de açúcar branco com que se fazem figuras como a pomba (símbolo do Espírito Santo). Cascudo informa que, muito antes do século XVI, o alfenim já era tradicional na antiga nobreza portuguesa, acompanhando a festa do Espírito Santo. Acrescenta que é também doce de romarias, inseparáveis dos arraiais. No Brasil, no Nordeste, diz ser gulodice democrática, exposta ao público em todas as festas religiosas e vendido nas ruas, e que as flores e figurinhas que enfeitavam os bolos de noiva e outros eram também feitas em ponto de alfenim ${ }^{7}$. Segundo este autor, a doçaria é o elemento mais importante da influência portuguesa na cozinha brasileira, acompanhando as festas religiosas e populares (tal como acontece em Portugal, na Madeira, nos Açores, nas Canárias, em Cabo Verde e em S. Tomé e Príncipe). O alfenim adquiriu grande significado cultural no Nordeste brasileiro, onde teve início a colonização portuguesa e a cultura açucareira. Sobre o alfenim, no Nordeste, Freyre escreve:

Os doces com feitio de homem e de animal, sempre muito encontrados nas feiras portuguesas, e dos quais Leite de Vasconcelos já escreveu que parecem "relacionar-se com antigas formas cultuais" comunicaram-se ao Brasil, sobrevivendo nos mata-fomes de tabuleiro e nos alfenins. Os mata-fomes em forma de cavalo, camelo, camaleão, homem ou mané-gostoso; os alfenins, em formas também de homem, menina, galinha, galinha chocando, pombinhos, cavalo. Doces hoje raros mas que ainda se encontram no Nordeste. (...) As formas mais prosaicas de

\footnotetext{
${ }^{3}$ Melo 1972-1990 III: 358.

${ }^{4}$ Frutuoso 1977-1987, livro II, cap. 34: 103.

${ }^{5}$ Manuscrito 142 do Arquivo Distrital de Braga.

${ }^{6}$ Sainz-Trueva 1987: 21.

${ }^{7}$ Cascudo 1954: 50.
} 
alfenim chave, sapato de noiva, pilãozinho, cachimbo. Tudo isso está desaparecendo. Tornando-se mera curiosidade etnográfica. ${ }^{8}$

Atualmente, o alfenim é cada vez mais raro nas festas religiosas e populares do Nordeste brasileiro, fazendo parte da doçaria tradicional como lembrança de sabores da infância, que as pessoas compram mantendo a tradição.

Em finais do século XV, a ilha da Madeira produzia já uma grande quantidade e variedade de confeitos e conservas que exportava para a Europa. Os frutos poderiam ser conservados numa calda de açúcar, designada por "casca molhada”, ou cristalizados, "casca seca". Na conserva do fruto da cidreira, usavam a casca da cidra, chamada cidrão, para fazer o doce de cidra em calda ou como doce seco em fatias cristalizadas. A designação de casquinha era adotada para a conserva feita a partir do limão ou da cidra ${ }^{9}$. Os documentos históricos registam as várias denominações das conservas e confeitos produzidos na ilha da Madeira, atestando tratar-se de uma verdadeira indústria ${ }^{10}$.

O açúcar era um produto de luxo privilegiado na mesa da nobreza e do clero. Através dos livros de receita e despesa dos conventos da Madeira, podemos acompanhar o dia a dia da mesa e doçaria conventual de Santa Clara, das Mercês e da Encarnação. O livro de receita e despesa do Convento da Encarnação, nomeadamente de 1813-1814, regista um grande consumo de açúcar e, consequentemente, uma grande quantidade e variedade de doces. Entre outros, em 1814, encontramos a alféloa (doce também de origem árabe, alfelô, alfeolo ou felô no Brasil e em Portugal alféloa e alféola), um dos doces mais antigos e mais típicos, muito popular pela sua simplicidade de fazer e comer: "pasta de mel ou açúcar em 'ponto grosso', esfriam-no manipulando, puxando-o, até embranquecer. Torcem-no como uma coluninha salomónica. Vendido embrulhado em papel" ${ }^{11}$. No Convento da Encarnação da Madeira, este doce surge a par do bolo de mel e do bolo doce, assim como do caramelo, da rapadura, da talhada de amêndoa, da marmelada, das cavacas, broas, sonhos ("10 libras de açúcar nos sonhos pelo Entrudo"), do doce de peras e das queijadas ("requeijão para as queijadas"). Veríssimo, ao referir o Convento da Encarnação do Funchal, registou como doces do Entrudo da Quaresma "malassadas, sonhos, meladas e coscorões" e, no Dia de Maio, "rapaduras e alféola". Segundo o mesmo autor, nos Livros de Gastos da Santa Casa da Misericórdia do Funchal, são referidos "bolos de mel" no Natal e "malassadas" no Entrudo ${ }^{12}$. Sainz-Trueva regista, entre os doceiros e confeiteiros da ilha,

\footnotetext{
${ }^{8}$ Freyre 1997: 77 e 80.

${ }^{9}$ Ribeiro 1993: 345.

${ }^{10}$ Cf. Nunes 2003: 585-622.

${ }^{11}$ Cascudo 1954: 50.

12 Veríssimo 1987: 43 e 45.
} 
o Papa, velhote que vendia doces e "rebuçados de mel de cana" pelas ruas da cidade do Funchal. Estes rebuçados seriam as "rapaduras" ou "meladas"

$\mathrm{Na}$ Madeira, originalmente, rapaduras eram os restos de açúcar caramelizados que ficavam no fundo dos tachos, onde se concentrava o sumo da cana, e que eram rapados e aproveitados como rebuçados. Este termo parece ter sido conservado na ilha até meados do século XX, conforme Sarmento. Ao falar sobre "a arte dôce", refere a apetecida guloseima vendida na rua com o pregão: "Ra-pa-duras! - cá estão as rapaduras do Papa... Quem não tem dinheiro não compra rapaduras", informando que o velho que as vendia assemelhava-se a Pio IX, imagem difundida em gravuras, e daí o "apelido" (alcunha) que lhe ficou e ajudava a ter fregueses. O autor define as rapaduras como "rebuçados feitos de mel de cana, pegajosos, envoltos em papel franjado", acrescentando que vinham quentes e era um "despejar de cabaz, várias vezes por dia”. Menciona igualmente os doces de fruta de abóbora, boganga, pepinela, amoras dos silvados, e uvas vermelhas da serra, o mel do figo branco da rocha, a goiabada, marmelada, bananada, nesperada, etc. ${ }^{14}$. Curiosamente, Cardoso apresenta uma receita de um doce chamado raspaduras (variante de rapaduras), feito de açúcar, coco e água, cozido numa panela até o ponto de espadana ${ }^{15}$.

Sobre a palavra rapadura, Pérez Vidal ${ }^{16}$ assinala que grande parte dos portugueses estabelecidos nas Canárias eram da Madeira, donde se levou o cultivo da cana e a indústria açucareira e conserveira, os agricultores especializados e os mestres de fazer açúcar. Por isso, é sobretudo na ilha de La Palma, a mais aportuguesada de todas, que encontramos grande quantidade de palavras portuguesas. As ilhas Canárias, sobretudo a ilha de La Palma, têm uma grande tradição de conservas de fruta, tal como a ilha da Madeira, conforme podemos observar na documentação histórica, onde encontramos termos como: "confites y conservas", "confites e confituras", "conserva", "conserba de calabacete", "conserva de pera”, "conserva de diaçitrón” e "fruta de azúcar" ${ }^{17}$. Sobre a rapadura, denominação com a forma portuguesa, Pérez Vidal escreve:

Esta forma rapadura se ha conservado hasta hoy en Canarias, sin convertirse en raspadura como en algunas otras áreas de habla española, porque muy pronto dejó de referirse a un producto que se obtenia raspando (...) ya sólo designó un

\footnotetext{
${ }^{13}$ Sainz-Trueva 1987: 21.

${ }^{14}$ Sarmento 1941: 6-7.

${ }^{15}$ Cardoso 1994: 56.

${ }^{16}$ Pérez Vidal 1991.

${ }_{17}$ Nunes 2001: 154-157.
} 
producto de confitería: un género de pequeños pilones en los que al azúcar se añade café, o huevo, o chocolate... también hay rapaduras de miel y gofio. ${ }^{18}$

O autor afirma que a rapadura de miel é a primitiva, ou seja, a rapadura tradicional é a "negra", a rapadura de gófio com mel de cana, feita com os ingredientes típicos: gofio, mel de cana, limão e canela, sendo o mais popular de todos os doces da confeitaria das Canárias ${ }^{19}$. Em "Conservas y dulces de Canarias", o autor explica que a "rapadura de gofio y de miel cocida", à qual se pode juntar amêndoas tostadas, é a chamada rapadura de gofio, "farinha de cevada, milho ou trigo, ou mistura dos três cereais tostados" ${ }^{20}$. Nas Canárias, a produção de rapaduras teve o seu principal centro em La Palma, ilha com maior presença de madeirenses e, talvez por isso, a mais dedicada ao fabrico de rapaduras e outros doces. A rapadura foi tão importante que se tornou o doce típico, tendo a forma de cone, porque solidifica em pequenos moldes de barro cónicos, lembrando a forma do pão de açúcar da antiga produção açucareira. Pérez Vidal explica como se teria passado das primitivas rapaduras para as rapaduras atuais:

mandaban refinar las rapaduras, esto es, hacer com ellas panes; pero estos panes, por mucho que se les refinase, debían de tener ya una cristalización muy baja; un aspecto, más que de azúcar, de miel solidificada. Y a este producto, siguiendo un proceso semántico muy corriente, se le llamó también rapadura. Así se debió de llegar a la canaria rapadura de miel, la más primitiva y popular de todas. (...) el paso de esta rapadura de miel a la rapadura de gofio resulta bastante fácil de explicar. La rapadura no era, como ahora, una golosina exclusivamente infantil. Servía, además, por su bajo precio, de azúcar y alimento a la gente pobre. (...) Este empleo alimentício de la rapadura pudo originar la rapadura de miel y de gofio. La miel con el gofio alimentaba más; y el gofio con la miel se pasaba mejor. ${ }^{21}$

Hoje, já existem diferentes variedades de rapaduras da ilha de La Palma, à base de leite, com vários sabores, como chocolate, café, baunilha, menta, amêndoa e coco, nomeadamente rapaduras feitas de açúcar, amêndoas, ovos, limão ou leite, ovo e açúcar, com vários sabores ou ingredientes. Pérez Vidal refere ainda a existência da rapadura no Brasil e em toda a América latina (como raspadura), por exemplo na Venezuela, onde é feita em pequenos trapiches, como produto popular e caseiro ${ }^{22}$. No Nordeste brasileiro, a rapadura tornou-se o alimento mais rico da pobre dieta do sertão, sendo consumido

\footnotetext{
${ }^{18}$ Pérez Vidal 1991: 231.

${ }_{19}$ Pérez Vidal 1983.

${ }^{20}$ Pérez Vidal 1947: 240.

${ }^{21}$ Pérez Vidal 1981: 182-183.

22 Pérez Vidal 1991.
} 
como substituto de carne ou peixe e, misturada com farinha, como fonte de energia para o trabalho. Rabelo ${ }^{23}$ indica que, no Nordeste, a rapadura deixou de ser um subproduto e passou a ser um produto com as mesmas propriedades do açúcar mascavo ou mascavado. Freyre acrescenta:

Com rapadura é que se fazem no Nordeste sertanejo doces de banana, de goiaba, de araçá, de caju, de abacaxi, de laranja, de guabiraba, de buriti, de leite e ovos; e junto com mel de rapadura, isto é, rapadura derretida ao fogo, se saboreia, como no próprio Nordeste açucareiro, inhame ou macaxeira, ou apenas farinha. (...) $\mathrm{O}$ mel de engenho ou melado, que é o açúcar na sua primeira forma, é misturado à farinha e acompanha a macaxeira ou mandioca, cará ou inhame, pão ou queijo. ${ }^{24}$

O autor afirma ainda: "Sem açúcar - seja do mais refinado ao mascavo, ao bruto ou de rapadura - não se compreende o homem do Nordeste.". Tal como na Madeira, o açúcar foi tão importante na formação da índole do povo brasileiro que o padre António Vieira disse ser o Brasil açúcar, como refere Freyre. O português do Brasil também ficou conhecido pela expressão de Eça de Queirós "português com açúcar" 25 , sublinhando a especificidade do falar e, ao mesmo tempo, aludindo ao seu glorioso passado de produtor açucareiro.

Antonil descreve o fabrico da rapadura como resultado de uma série de operações: do mel apurado nas tachas saem diferentes têmperas, ou seja, três tipos de açúcar, dos quais o último, mais batido do que os primeiros, se transforma em rapadura. $\mathrm{O}$ autor explicita "O melado que se da em pratos e vasilhas para comer, he o da primeira e segunda tempera. Do da terceira bem batido na repartideira se fazem as rapaduras, tam desejadas dos meninos: e vem a ser melado coalhado sobre hum quarto de papel com todas as quatro partes levantadas, como se fossem paredes, dentro das quaes endurece esfriando-se" ${ }^{26}$. No processo de cozedura do sumo da cana para fazer rapadura, o líquido grosso após as primeiras fervuras constitui o mel de cana que endurece um pouco e fica no ponto de puxa, bolinha acaramelada que é guloseima comida na hora. Depois, da massa que está na resfriadeira, é feito o requintado alfenim, doce branco resultante do manusear da pasta, que o mestre amassa como se sovasse um pão, adicionando água até alcançar a consistência de esculpir em várias figuras, e o doce vai clareando. O último derivado, antes da rapadura, é a chamada (rapadura) batida: à massa pastosa juntam-se especiarias (canela, cravo ou gengibre), sendo depois enrolada

\footnotetext{
${ }^{23}$ Rabelo 1969.

${ }^{24}$ Freyre 1997: 28-29.

${ }^{25}$ Jornal As farpas, fevereiro de 1872.

26 Antonil 1711: 74.
} 
na palha da própria cana. Por fim, com o choque térmico da resfriadeira, a rapadura pura cristaliza, sendo deitada em formas de madeira, ficando com a forma de barra açucarada tipicamente brasileira.

Para Bluteau ${ }^{27}$, raspadura é o que se tira rapando, sendo sinónimo de raspa, o que se tira com raspador. Morais Silva ${ }^{28}$ define a palavra rapadura ou raspas, no Brasil, já como "massa dura de açúcar ainda não purgado ou de mascavado coagulado, na qual se lançam amendoins", corrigindo a forma raspadura e afirmando que o termo correto é rapadura, por ser uma palavra derivada de rapar e não de raspar. Domingos Vieira ${ }^{29}$ afirma que o termo rapadura é um brasileirismo, apresentando a mesma definição de Morais Silva. Figueiredo ${ }^{30}$ informa que rapadura, no Brasil, designa o açúcar mascavado, coagulado em forma de pequenos tijolos quadrados. Caldas Aulete ${ }^{31}$ também classifica o termo rapadura como brasileirismo, com a variante raspadura ou raspas, definindo-o como "torrão de açúcar mascavado, resultante das rapaduras das caldeiras e pequenos tijolos ou ladrilhos de açúcar mascavado”. Rabelo ${ }^{32}$ diz- $^{-}$ -nos que o termo rapadura, no Nordeste do Brasil, é a forma mais frequente, mas que um pequeno número de pessoas idosas usa a forma raspadura, com $s$ intercalar, do verbo raspar (por influência do espanhol).

No Brasil, nomeadamente no Nordeste, o termo rapadura adquire uma nova aceção, denominando o melado concentrado, colocado em forminhas, geralmente quadradas e de madeira, formando tijolos de açúcar não purgado com as mesmas propriedades do açúcar mascavado, podendo ser rapadura pura ou rapadura misturada com frutas: mamão, abacaxi, tangerina, goiaba, coco e manga, e ainda rapadura batida com gengibre, canela, cravo e noz-moscada, quando se junta amendoim é pé de moleque.

Faz rapadura com mistura de amendoim, com coco, com goiaba, isso aí bota o que quiser; Rapadura tem que apertar mais. Ela tem que deixar ele ficar bem grosso. Aí, a gente bota... faço o ponto na água. Quando ele começa a ficar bem grosso, a gente bota uma colher dentro de uma vasilha com água, ele fica durinho. Quando ele fica durinho, tá pronto; É rapadura de amendoim que é o pé de moleque também. Só que é um pouquinho diferente. O pé de moleque leva um pouco mais de amendoim e a rapadura um pouco menos. A rapadura de coco, o processo dela é igual, só que daí põe o coco. Eles diz que o que tou fazendo é pé de moleque, porque a minha rapadura tem bastante amendoim.

\footnotetext{
${ }^{27}$ Bluteau 1712-1721.

${ }^{28}$ Morais Silva 1813.

${ }^{29}$ Domingos Vieira 1871-1874.

${ }^{30}$ Figueiredo 1899.

${ }^{31}$ Caldas Aulete 1881.

32 Rabelo 1969.
} 
Esta descrição é de um informante de Santo António da Patrulha, Rio Grande do Sul, Brasil. A recolha da terminologia açucareira atual do Brasil mostra-nos a conservação de alguns termos da antiga cultura açucareira madeirense nas áreas geográficas mais pobres e isoladas, sobretudo onde a rapadura é uma produção artesanal e familiar. Uma das áreas mais conservadoras é o Nordeste brasileiro, por ser a região de mais antiga produção açucareira. Em Pernambuco, um inquirido deu-nos a seguinte informação:

chamava rapa, o que rapavam pa comer. Metia a faca nas paredes do batedor. Aí, nas paredes criava o mel, passava a faca assim. Aí, caía aqueles pedação assim, fino, enxugava e ficava duro como a rapadura. Chamavam rapa e tiravam do batedor. Tirava muito pedaço pa comer e levava pa casa pa fazer café. Eu pegava o mel de rapa pa levar pa casa.

Esta descrição ainda parece aproximar-se muito da de Antonil. Curiosamente, quanto à rapadura, o Nordeste (Paraíba, Pernambuco e Baía) e o Rio Grande do Sul (RGS) são as áreas geográficas por nós inquiridas com maior produção e tradição rapadureira. No caso do RGS, as ligações comerciais de importação de açúcar do Nordeste brasileiro e o gosto pelo doce fizeram com que se desenvolvesse o fabrico de produtos açucareiros, sobretudo da rapadura.

Sousa afirma que a doçaria madeirense está diacronicamente conectada com o cultivo regional da cana sacarina, iniciado na segunda metade do século XV. Salienta os doces e conservas, as frutas cristalizadas e em calda, resultantes da indústria conserveira madeirense e da manufatura caseira e conventual, sobretudo o bolo de mel de cana, explicando que, à parte do bolo rico, generaliza-se a confeção de um género de bolo de mel menos elaborado, popularmente conhecido por "bolo de um dia". Acrescenta que o mel de cana é fortemente utilizado à mesa dos madeirenses pelo Natal (Festa) e Carnaval: "As razões desta sazonalidade devem-se, essencialmente, ao fabrico do bolo de mel, broas de mel e malassadas." ${ }^{33}$. A diversificação das receitas do bolo de mel, mais rico e pobre, deve-se às possibilidades económicas de cada família. Sainz-Trueva também confirma a existência de um "bolo de mel rico" (com cidra, passas, amêndoas e nozes) e um "bolo de mel pobre" ${ }^{34}$. Sousa aponta que o bolo de mel de cana era feito na época festiva do Natal pelo clero e famílias mais ricas, enquanto a forma popular de usar o mel de cana em doçaria era nas pequenas broas, feitas com o referido mel. As broas de mel exigiam apenas a erva-doce como especiaria e não as caras especiarias da Índia. O historiador escreve: "É no contexto social da nobreza e dos conventos a ela associados,

\footnotetext{
${ }^{33}$ Sousa 2012: 99-100.

${ }^{34}$ Sainz-Trueva 1987: 17.
} 
particularmente o de Santa Clara do Funchal, que o bolo de mel de canade-açúcar atinge a sua forma canónica ou típica." ${ }^{35}$. O autor acrescenta que a Madeira constava na rota dos navios para a Índia e, por isso, especiarias como o cravinho ou cravo-da-Índia, o cravo-Maranhão, a noz-moscada e a canela abundavam na ilha. A técnica de fabrico para longa conservação do bolo de mel da Madeira também recorda o abastecimento das naus da carreira da Índia. Deste modo, o bolo de mel de cana foi dos primeiros doces em que estas especiarias amargas foram introduzidas, bem como a pimenta moída, a canela, o gengibre, juntamente com os produtos europeus: erva-doce, passas, cidra, amêndoas, nozes, aguardente de cana, vinho Madeira, cerveja preta, laranjas, limão, manteiga, farinha de trigo e banha de porco.

Em Gastronomia Tradicional da Madeira e do Porto Santo, além do bolo de mel rico (com amêndoas peladas, nozes, passas, canela moída, cravo-maranhão, erva-doce moída, noz-moscada moída, cidra, etc.), assim designado pela quantidade e qualidade dos preparos, que era feito a 8 de dezembro (dia de Nossa Senhora da Conceição), encontramos o chamado Bolo da Festa, assim chamado porque o Natal na Madeira é a Festa e o mês de dezembro é conhecido pelo mês da Festa. Este Bolo da Festa é uma receita tradicional da Madalena do Mar (na ilha da Madeira), feito somente com açúcar, farinha, manteiga, leite, limão, ovos e soda, podendo juntar-se cacau (usado apenas no Natal, sendo ainda hoje tradicional beber cacau com leite no dia 25 de dezembro ao pequeno-almoço com a carne de vinho e alhos). Outra curiosidade era este bolo ser cozido no forno a lenha, o que mostra que se tratava de um bolo pobre, das pessoas mais humildes do campo, que não tinham acesso ao mel de cana, às especiarias e às frutas secas e cristalizadas.

Em Mel de cana sacarina, algumas das formas recomendadas de usar este produto são as "mal-assadas", os sonhos, as rabanadas, no pão como substituto da manteiga, com os frutos e misturado com papas. O livro mostra como o mel é imprescindível na doçaria madeirense, celebrizada através do bolo de mel da Madeira. Além do Bolo de Mel, dá-nos a receita do Bolo Barrete Preto (com mel de cana, café, leite, farinha, ovos, soda, noz-moscada, passas, nozes e cidra), das b(o)roas de mel e dos merengues com mel. O mel de cana e as especiarias também entram na confeção de muitos outros bolos feitos na Madeira: bolo (de) família (com ingredientes típicos do arquipélago, como o mel de cana, o vinho da Madeira, as frutas cristalizadas, as nozes, mas também noz-moscada e canela), bolo preto (a massa é enriquecida com mel de cana, frutos secos, ou cristalizados, canela, noz-moscada, vinho da Madeira e cerveja preta), bolo de cerveja (certamente por influência inglesa, o vinho da Madeira junta-se à cerveja e dá origem a um bolo igualmente escuro, enriquecido com

\footnotetext{
${ }^{35}$ Sousa 2008: 33.
} 
mel de cana, passas e nozes), bolo podre da Madeira (este também é muito parecido com o bolo de mel típico da Madeira, sendo feito com mel de cana, canela, passas, cidrão e/ou frutas cristalizadas e nozes). Esta variedade de bolos de mel de cana com frutas cristalizadas e especiarias revela bem o gosto e a importância dada pelos madeirenses à indústria açucareira e conserveira da região. Como podemos ver, trata-se de bolos muito semelhantes, com muitos ingredientes em comum: mel de cana, vinho Madeira, frutos secos e cristalizados, noz-moscada e canela.

Rebelo, ao escrever sobre o Bolo Família, diz que a designação "remete para a época festiva passada em família, o Natal", sendo muito semelhante ao Bolo de $\mathrm{Mel}$, tipicamente madeirense, inclusive pelos seus ingredientes, tendo contudo um tamanho maior que dá para toda a família e visitantes. A autora defende que a sua denominação derivará desse facto. Informa que o Bolo Família também existe no Brasil, o que se deverá aos emigrantes madeirenses que terão levado a receita, explicação muito plausível avançada pelos inquiridos, segundo Rebelo ${ }^{36}$. Deste modo, a autora não concorda com a explicação fornecida em Gastronomia Tradicional da Madeira e do Porto Santo, para a denominação deste bolo, que também é chamado Bolo Escuro Delicioso, indicando que, a seguir ao bolo de mel, o bolo família é dos mais apreciados em todo o Arquipélago da Madeira, devendo o seu nome, provavelmente, ao facto de a receita passar de mãe para filha e assim de geração em geração ou ao corte miudinho dos frutos secos, feito por toda a família ${ }^{37}$.

$\mathrm{Na}$ Ribeira Brava e na Ponta do Sol, os bolos doces tradicionais e populares da Madeira são feitos pelo Natal e nos casamentos, como retribuição pelos presentes oferecidos aos noivos. Trata-se de massa de pão temperada com "água moura" (com sal), açúcar, manteiga, banha de porco, leite, canela, noz-moscada, erva-doce, nozes, passas, soda, pimenta da terra moída, mel de cana e vinho Madeira, que, depois de sair do forno, se unta com manteiga ${ }^{38}$. Estes são denominados pão bolo de noiva, também chamados bolo da serra, por serem utilizados nas zonas rurais para os casamentos, e bolo de pimenta ou pimentinha, por levarem pimenta. A revista Folclore regista ainda o Pão Doce, que também se faz no Natal, com farinha, leite, açúcar, fermento, sal, soda, canela, passas, pimenta moída, erva-doce, batata-doce e folhas de couve, indicando que, após a amassadura, leveda e o pão depois é cozido com duas folhas de couve, para ficar mais "amoroso", no forno juntamente com o pão.

Figueira $^{39}$, além do Bolo Preto Rico, regista também o Bolo Funchal (com manteiga, açúcar, mel de cana, café, leite, farinha, ovos, nozes, passas, cidra e

36 Rebelo 2014: 643-644.

37 Gastronomia 2013: 84.

38 Folclore 1998: 26

39 Figueira 1993. 
soda), o Bolo Húmido, o Bolo Preto de Ameixas e o Bolo Preto Delicioso. No livro Cozinha madeirense, encontramos ainda Babas de mel de cana, Bolo de Cerveja Preta com mel de cana, Bolo Preto de Figos, Bolo Preto do Silva, Bolo Rico, Broas da Madeira com aguardente e vinho Madeira, entre outros. ${ }^{40}$ Cardoso regista Beteretes com mel de cana (séc. XIX), broas de mel de cana com noz ou passas, bolo Madeira quente (com mel de cana e frutas cristalizadas), bolo de pão torrado com mel de cana, bolo de nozes com mel de cana, bolo de laranja com mel de cana, bolo de figos com mel de cana, bolo branco e preto com mel de cana e bolo saboia com um cálice de aguardente de cana ${ }^{41}$. É importante notar também o hábito das Rabanadas, que Freyre diz serem chamadas Fatias-de-Parida na Baía, comidas pelo Natal ${ }^{42}$. Na Madeira chamam-se Douradas, no entanto Cardoso regista uma receita de Fatias de Parida como doce conventual, sendo que estas se distinguem das Douradas pelo facto de as fatias de pão serem ensopadas no vinho aquecido em vez do leite ${ }^{43}$.

Outro doce que não podemos deixar de referir é a malassada. Aquando da nossa recolha linguística e etnográfica na ilha de La Palma, como doces típicos ou tradicionais do Carnaval, encontrámos a sopa de miel: "En Carnaval se hace la sopa de miel, hecha de miel de caña, almendra, pan, limón y canela." (Los Sauces), "Otra cosa que es muy de aquí, de la miel, en el Carnaval, es la sopa de miel: pan con miel, con limón y con almendras." (Los Llanos de Aridane) e a malasán ou malasada: "Aquí tenemos la malasán o malasada, es una torta de gofio o harina con miel de caña. Se come en dias especiales como en Carnaval." (Los Llanos de Aridane) ${ }^{44}$, sendo um doce palmeiro que curiosamente parece não ter sido registado por Pérez Vidal, nos seus vastos estudos sobre a tradição açucareira canária. Na Madeira, Cardoso também regista uma receita de soupa doirada, que classifica como conventual e popular pela sua forma gráfica. Este doce é feito de açúcar, miolo de pão, gemas de ovos, colheres de manteiga, canela e amêndoas peladas e picadas, cozidos numa calda, deitados numa travessa e polvilhados com canela. Informa que se come frio, cortado aos quadrados ${ }^{45}$. No Brasil, em Freyre, também encontramos referência à chamada sopa dourada que se fazia no Carnaval, no Nordeste, juntamente com os sonhos ${ }^{46}$. Logo, a sopa de miel também será um portuguesismo, pois a maior parte dos portuguesismos documentados

40 Figueira 1997.

41 Cardoso 1994: 51, 69, 70 e 72.

42 Freyre 1997: 205.

43 Cardoso 1994: 48.

44 Cf. Nunes 2010.

45 Cardoso 1994: 88.

46 Freyre 1997: 205. 
nas Canárias, principalmente na ilha de La Palma, são termos da ilha da Madeira, como malasada.

Segundo o Dicionário Houaiss da Lingua Portuguesa, a primeira atestação da palavra malassada (formada de mal e assada) data de 1609. No Brasil, a palavra existe, mas é sinónimo de "fritada", massa de ovos batidos cozida na frigideira, conforme o Novo Aurélio século XXI. Registámos a primeira atestação do termo malasadas na documentação histórica da Madeira, mais especificamente nos livros de receita e despesa do Convento da Encarnação (1688, 1705, 1756 e 1762), em 1762: "Para coscorões: sonhos e malasadas um alqueire" ${ }^{47}$, sendo um doce que ainda hoje encontramos na ilha da Madeira, "come-se as malassadas com mel de cana no Entrudo" (Machico). Em Gastronomia Tradicional da Madeira e do Porto Santo, sobre o nome malassadas, diz-se que "O termo indica quer o facto de a massa no interior não cozer totalmente (mal assadas), quer o facto de a cor exterior, depois de fritas, se dever manter clara." ${ }^{48}$. No livro Receitas com mel-de-cana, além das malassadas com mel de cana, bolo de mel da Madeira com nozes e mel de cana e broas da Madeira com mel de cana, encontramos queques de cenoura com mel de cana, capelas do Porto Santo com mel de cana, bolinhos de laranja com mel-de-cana, entre outros doces ${ }^{49}$. Na Madeira, as malassadas são comidas com mel de cana, característica da cultura madeirense, como resultado da produção açucareira regional, tal como o inhame e outros alimentos.

Freyre diz-nos que, no Nordeste brasileiro, nos dias de Carnaval, comiam-se as velhas filhoses portuguesas com mel de engenho ${ }^{50}$. É curioso que, tanto na Madeira como nos Açores e no Brasil, as malassadas ou filhoses sejam comidas no Carnaval e não nas festas do Natal e final de ano, e com mel de cana, no caso da Madeira e do Brasil, locais onde existe produção de mel de cana ou mel de engenho (Brasil). As malassadas (mal-assadas), o mesmo que filhós ou filhoses no continente português, também existem com esta denominação no Havai, tendo sido levadas pelos portugueses que emigraram da Madeira e dos Açores (ilha de S. Miguel), a partir de 1878, para trabalharem nas plantações de cana-de-açúcar. As famílias açorianas e madeirenses comiam malassadas, especialmente na terça-feira de Carnaval ou terça-feira gorda (antes da quarta-feira de Cinzas) e, devido à sua grande difusão, esta tradição portuguesa deu origem ao Dia da Malassada (Malasada Day) no Havai.

\footnotetext{
${ }^{47}$ Sousa 1948: 51.

${ }^{48}$ Gastronomia 2013: 88.

${ }^{49}$ Freitas 2008.

${ }^{50}$ Freyre 1997: 73.
} 
Voltando às Canárias, assim como a rapadura é o mais importante dos doces canários herdados dos madeirenses, o gófio foi o mais conhecido alimento de herança guanche na Madeira. O gófio dos guanches foi a base da alimentação popular das Canárias. Este era feito de cevada e foi mais tarde, com a introdução dos outros cereais, que se generalizou o gófio de trigo e de milho. O gófio é feito de cereais tostados e moídos, sendo a farinha típica das Canárias, que tem um gosto especial e alto valor nutritivo, usado nas papas com leite para as crianças e como fortificante. Frutuoso narra que na ilha de La Palma todos se dedicavam à criação de cabras e ovelhas, e comiam gófio de trigo e cevada, amassado com azeite, mel e leite. Explica que tostavam o trigo e a cevada em tostadores de barro e tinham moinhos de mão pequenos em que moíam os cereais. Refere ainda que a farinha de cevada do dito gófio, amassada com mel e óleo, nutria, purificava e engordava, pela sua excessiva energia ${ }^{51}$. Atualmente, nas Canárias, faz-se gófio de todos os cereais, sobretudo de milho (por exemplo, no prato típico rancho). O gófio ou gofe foi integrado na gastronomia e na cultura das Canárias e teria chegado ao Arquipélago da Madeira através do contacto com os escravos guanches. Veríssimo afirma que, no século XVIII, o consumo de gófio ocorria no Porto Santo e fazia parte da ementa do Convento da Encarnação. Com base na documentação histórica da Madeira, informa que o Convento da Encarnação do Funchal possuía vastas propriedades no Porto Santo, e daquela ilha as freiras recebiam, entre outros, cevada e gofe. Explica que com a cevada se fazia o gófio (farinha torrada) e que, nos livros do convento, ficaram anotados entre as despesas diversos "taleigos de gofe que veio do Porto Santo". O autor acrescenta que a larga exploração do gófio determinou em 18 de agosto de 1780, uma postura municipal a proibir o seu fabrico no Porto Santo: “(...) huma especie de farinha a que chamam gofe para hum alqueire da qual sam precizos coatro de sevada que para este fim se apanha verde consestindo perjuizo (...)". Veríssimo indica ainda que com o gófio e leite de cabra ou de vaca se faziam papas, mencionando que esta especialidade alimentar parece ter sido introduzida na Madeira por escravos vindos das Canárias ${ }^{52}$.

Morera refere, entre outros nomes comuns de procedência guanche, o gófio com as variantes gofe e gofo. O autor define gófio como "Refeição preparada com cevada torrada ou trigo (Silva 1950, s. v. gofe)." ${ }_{53}$. Informa que foi um alimento muito comum entre os habitantes de algumas povoações do Arquipélago da Madeira: "Ainda se fabrica gófio no Porto Santo, mas

\footnotetext{
${ }^{51}$ Frutuoso 1977-1987, livro I, cap. 14: 96.

${ }^{52}$ Veríssimo 1987: 41.

${ }^{53}$ Morera 1992: 11.
} 
em diminuta quantidade, somente para uso particular na alimentação de crianças, débeis e doentes.". Branco diz ter comido gófio em menino, tanto no Porto Santo como em Santa Cruz, na ilha da Madeira: "Era farinha cevada moída, cozida em leite, no Porto Santo de cabra, em Santa Cruz de vaca. Lá em casa, a criançada pulava por tal manjar; o sabor lembrava ao da farinha Nestlé, usada em papas para criancinha." e acrescenta: "Na Madeira, nunca encontrei tal papa fora de nossa casa, mas a Madeira não é ilha diminuta e afinal, conheço tão pouco dela e de seus habitantes; pode muito bem ser que nas costas de baixo ou no norte o gófio fosse usado antigamente. ${ }^{54}$. Esta observação confirma a necessidade de fazermos recolhas orais de relatos de memórias sobre este património alimentar que se perdeu, assim como de outras receitas tradicionais que ainda não se encontram registadas. Em Memórias com história, encontramos um registo de "Papas de farinha torrada", em que se "torra a farinha numa panela, depois junta-se o leite e vai ao lume a ferver até ficar consistente. Se quiser, junta-se um pouco de açúcar." ${ }_{55}$. Esta descrição parece aproximar-se do gófio. Também na Cozinha tradicional da ilha Terceira e de S. Miguel encontramos "papas de farinha torrada", que são feitas com farinhas de milho ou trigo torradas ou com a mistura das duas, também para crianças ${ }^{56}$.

Cardoso refere a abundância cerealífera de outrora em trigo, centeio, milho e cevada, assinalando que muitos são os pratos já desaparecidos, como as sopas da "panela" de saramago, gofe, frangolho, etc. Informa que "a cevada torrada era aproveitada para a sopa de gofe (Monte e Camacha).”. A autora dá-nos a receita da sopa de gofe do Monte (água, cenoura picada, nabo, cebola, feijão ou feijoca, batata doce picada, folhas de couve picada, pedaços de abóbora amarela ou moganga, carne de porco e carne de vaca salgada, cevada torrada moída e peneirada). Indica que a sopa fica enxuta e dura como o "milho", tem cor escura, paladar áspero e cheiro a cevada. Come-se frito ou às talhadas. Informa também que "Nos primórdios do povoamento era preparado tão sólido e em forma de bola, sendo utilizado por pastores e camponeses na sua alimentação." ${ }^{57}$. Refere ainda que esta receita foi muito popular na freguesia do Monte, no século XIX. Mata descreve "O gófio da Ti Joaquina”, que era feito no Caniço de cima (ilha da Madeira):

A minha bisavó chamava-se Joaquina e sabia fazer gófio. Nunca provei essa estranha comida, mas sinto que a saboreei muitas vezes, à boleia das memórias da infância da minha mãe. A minha bisavó Joaquina fazia gófio com centeio,

\footnotetext{
${ }^{54}$ Branco 1995: 223.

55 Memórias 2012: 24.

${ }^{56}$ Gomes 1982 e 1987: 38 e 40.

${ }^{57}$ Cardoso 1994: 14, 16 e 31.
} 
que semeava, mondava, ceifava, malhava. Antes de levar ao moinho os grãos de centeio, torrava-os numa panela. A farinha de centeio era deitada dentro de um alguidar, enquanto a minha bisavó fazia à parte, na panela de ferro colocada sobre o lar, um guisado com muita cebola, tomate, feijão e outros legumes (...) Quando o guisado ficava pronto, deitava o conteúdo da panela dentro do alguidar e amassava-o juntamente com o centeio, até ficar com a consistência ideal. Então, fazia bolas redondas com a mistura do alguidar." Gófio um prato que julgo não ser confecionado há muito tempo na Madeira, pelo menos nunca o vi em lugar nenhum nem ouvi falar dele, a não ser nestas memórias maternas. ${ }^{58}$

Em Cabo Verde, também houve uma produção açucareira importante que permitiu o desenvolvimento da indústria conserveira. Como atesta Frutuoso: "A ilha de Santiago dá muito açúcar e fazem-se nela muito boas conservas, ainda que nada disto chega ao da ilha da Madeira." ${ }^{59}$. Ainda hoje existe grande tradição doceira, sobretudo na ilha de Santo Antão, sendo obrigatório referir o doce de papaia (verde e madura) feito com mel de cana em vez de açúcar, assim como os doces de goiaba, de manga e de tâmaras, comuns ao Nordeste brasileiro. Na Madeira, Cardoso regista o fabrico tradicional de doce de papaia verde com açúcar e um pau de canela ${ }^{60}$. Na publicação regional Cozinha Madeirense, também encontramos o doce de papaia com açúcar, laranja e limão e doce de papaia verde somente com papaia e açúcar, bem como o doce de banana verde $e^{61}$. Em Cabo Verde, o mel de cana, além de ser usado nos doces, sobretudo de papaia (em Santo Antão), é usado em bolos e bolinhos ou broas, que são doces tradicionais: bolo de mel de cana, bolinhos ou broas de mel de cana, cocada e/ou (a)çucrinha (de mel), bolo de cuscuz com mel de cana, bolinhos de mandioca com mel de cana. O bolo de mel de cana de Cabo Verde não é tão rico como o da Madeira, sendo feito apenas com farinha, mel de cana, manteiga, erva-doce, canela e raspa de limão. Na ilha de Santo Antão, é muito popular o (a)çucrinha (de mel), termo que denomina um doce feito de açúcar, de mel de cana ou de escumas de mel (com amêndoas ou amendoim), sendo muito semelhante à rapadura da ilha de La Palma e às rapaduras brasileiras. O termo (a)çucrinha é sinónimo de raspadura, como explica um informante da ilha de Santiago: "tem a raspadura do tacho, é a raspa, é çucrinha". Ou seja, o mesmo conceito é denominado "raspadura do tacho ou de cobre", "raspa", mas também "caramelo de mel", "açúcar di cobre", "cocorota di mel" e "cocorota di açúcra”. A (a)çucrinha pode ser feita com vários frutos, como por exemplo: çucrinha de banana e çucrinha de coco. Cardoso, ao escrever

\footnotetext{
${ }^{58}$ Blogue O_Rabo_do_Gato.

${ }^{59}$ Frutuoso 1977-1987, livro I, cap. 21: 117.

${ }^{60}$ Cardoso 1994: 41.

${ }^{61}$ Figueira 1997: 96-97.
} 
sobre "O açúcar nas ilhas", para Cabo Verde, entre outros doces, refere os rebuçados feitos de mel, chamados rebuçada, sucrinha de cacau e sucrinha de leite $^{62}$. Na ilha de Santo Antão, existe ainda o refilão ou puxador que parece ser uma espécie de alfenim, como podemos ver pela descrição fornecida por um informante sobre o modo como este é feito:

O senhor dá aquele escuma pa fazê um refilão, um puxador. Ponte de rebuçado põe-se na caldeira, vai-se dando lume e limpando até açucarar, põe-se no ponto de rebuçado, nuns pratinhos que a gente já tem preparado com um pouco de manteiga ou de azeite. Chama refilão porque é duro e pega, é puxador, nós dizemos normalmente vou fazer um puxador ou vou fazer um refilão.

Ao percorrermos a ilha de $\mathrm{S}$. Tomé à procura de informantes conhecedores e fazedores de produtos açucareiros, constatámos que os que conheciam e se dedicavam a esta atividade eram cabo-verdianos e os seus descendentes, ou excecionalmente algum santomense que tenha aprendido com os cabo-verdianos, por isso as técnicas e a terminologia utilizadas são as mesmas. Os cabo-verdianos de $\mathrm{S}$. Tomé foram levados para trabalharem nas roças de cacau e são muito pobres, tal como a grande parte da população são-tomense. Em S. Tomé, fazem um pouco de mel de cana, na panela, em casa, sobretudo para o doce de papaia com mel, tradicional de Cabo Verde. Os cabo-verdianos mantêm a tradição e vivência da memória da sua terra através do doce de papaia ou doce de mamão, com mel ou açúcar, que também chamam marmelada; do bolo de mandioca - "Faz bolo de mandioca com mel. Bate mel com fermento, com farinha de mandioca, cozinha bolo, fica bom bolo!"-; do doce de mandioca com mel, chamado mandioca de mel - "fervemos mandioca no mel, dentro do mel, é mandioca de mel" -; do açucrinha - doce de coco, doce de banana madura (feito na panela com açúcar) -; do pão com mel de cana; do bolo com cobertura de mel de cana; do cuscuz com mel; da batata com mel; do inhame com mel e da camoca (com mel), típica de Cabo Verde, que é farinha de milho, torrado e pilado no pilão, misturada com mel de cana ou com açúcra (da terra). Sobre a camoca em Cabo Verde, Filho escreve: "A camoca é preparada com milho torrado e depois reduzido a farinha, que se come com café ou leite adoçados com açúcar ou mel, disso resulta um excelente fortificante (...)." ${ }_{63}$. Posto isto, a camoca enquanto fortificante, feita de farinha de milho torrado, comida com mel de cana e com leite, lembra o gófio das Canárias. Quando falta o mel de cana, usam o açúcar queimado na panela ("mascavar açúcra branca pa torna castanha escura") para fazer a camoca, os doces de fruta, o bolo de mel e a ponche de mel. $\mathrm{Na}$ lha de Santiago, fazem o cuscuz de milho,

\footnotetext{
${ }^{62}$ Cardoso 1994: 156.

${ }^{63}$ Filho 1997: 202.
} 
doce tradicional na véspera do Dia de Cinzas, celebração importante, como nos relata um informante:

Nas vésperas de Cinzas, no mês de fevereiro, uma grande festa, fazem cuscuz com mel. Primeiro é tirar a camada superior do milho, que é farelo. Depois deitar água quente, de tarde até de manhã. Milho já está mais mole. Pilamos no pilão, depois é com balaios, deitamos a farinha fina. Depois num recipiente, colocamos um bindi di cuscus (um recipiente de barro que é furado). Quase se deita a farinha, a água que ferve debaixo começa a infiltrar só o vapor. Só depois de cozido é servido com mel na prato. Chamamos cuscuz com mel. Também pode comer o cuscuz com açúcar e canela, é muito saboroso.

Em Cabo Verde, o cuscuz é feito de milho porque naquela latitude o trigo não é produtivo, enquanto na Madeira é a partir da farinha de trigo que se faz o pão, os doces e o cuscuz. Braga, ao estudar os confeiteiros, cujo ofício é "fazer e vender doces", refere também os "alfeoleiros, biscoiteiros, pasteleiros, a par de muitas mulheres igualmente dedicadas à doçaria específica como a aletria, o arroz doce, o cuscuz (que podia ser doce ou salgado) e as conservas de fruta." ${ }^{64}$. Na Madeira, atualmente, o cuscuz é conhecido apenas como prato salgado e não encontrámos referência ao cuscuz como doce. Veríssimo refere que, no Convento da Encarnação do Funchal, "No Dia de Jesus ou nos Reis nunca faltava o picado de carneiro com cuscuz.". O trigo era empregue em pão, bolos, doces, empadas, pastéis e cuscuz. Por exemplo, no ano de 1769, as freiras consumiram $6^{1 / 2}$ alqueires de cuscuz ${ }^{65}$. Segundo Rezende, em Canhas e Câmara de Lobos, o cuscuz é um:

Alimento madeirense preparado com um quilo de fermento, misturado com um alqueire de farinha e um pouco de água morna, temperada com sal e folhas de segurelha. Assim que a farinha está aos grãos e sem humidade é deitada numa masseira, onde é ralada para acentuar a granulação. Depois, é metida num cuscuzeiro, panela de barro, com o fundo oval crivado de orifícios e semelhante até certo ponto com uma assadeira de castanhas, forrado com uma toalha, o qual é metido numa panela meia de água e com pedaços de louça partida no fundo. O cuscuzeiro não deve tocar a água, pois o cuscus é cozido no vapor. Os cacos servem para, ao chocalharem, indicarem que a água ferve. Depois de cozido o cuscus é novamente esfregado, enquanto quente é passado por um ralador e posto a secar. ${ }^{66}$

O Visconde do Porto da Cruz diz-nos que há dois pratos: o "cuscus vulgar" e o "cuscus rico". O primeiro come-se só com água, sal, um raminho

\footnotetext{
${ }^{64}$ Braga 2014: 166.

${ }^{65}$ Veríssimo 1987: 39-40.

${ }^{66}$ Rezende 1961: 282-283.
} 
de segurelha, manteiga e serve-se quente e o segundo é feito do mesmo modo mas come-se com passas de uva, azeitonas, pedaços de chouriço, de carne de porco, de carne de galinha e até conservas de pepino e couve-flor. Sobre a origem do cuscuz na Madeira e o seu modo de fabrico artesanal, o autor escreve:

O cuscus - parece que foi introduzido na culinária madeirense pelos escravos mouros do tempo dos povoadores - é dos pratos mais divulgados: farinha, água morna temperada com sal e com uma vassourinha de sigurelha vão burifando a farinha e sacudindo o alguidar assim se vão formando as pequenas bolas de massa crua que depois se retiram para dentro de uma toalha de linho em que vão para o cozimento no cuscuseiro, ou seja, num grande recipiente de barro, no género de panela com fundo côncavo e com um crivo largo. Este cuscuseiro é colocado na boca de uma grande panela e as bolinhas de massa ali cozem, dentro da toalha de linho, no vapor de água, durante algumas horas. Depois é exposto ao sol para secar. ${ }^{67}$

Na Madeira, o cuscuz é uma espécie de farinha granulada que é cozida num cuscuzeiro semelhante ao bindi de cuscuz cabo-verdiano. Cardoso informa sobre a preparação artesanal dos grãos de cuscuz e sobre a sua forma de cozinhar na Madeira, mencionando que os grânulos de farinha de trigo são cozidos enxutos para servir como arroz, especialmente na quadra do Natal e na Páscoa, com pratos de carne.

Trazido do Norte de África, depois muito usado na Madeira e Porto Santo foi alimento dos pobres muito vulgarizado na Ponta do Sol, Ponta do Pargo e Calheta. Foi também manjar senhorial. Daí haver o cuscuz rico, quando adicionado com pedaços de carne de porco, vaca, galinha, chouriço, passas, legumes e azeitonas em conserva. ${ }^{68}$

$\mathrm{Na}$ ilha da Madeira, por exemplo em Machico, o utensílio redondo de folha crivado de orifícios, "bola de (cozer) arroz" (introduzido na água do cozido para cozer o arroz), é chamado cuscuzeiro. Porquê este nome? Pela semelhança com o cuscuzeiro com orifícios no fundo para a entrada do vapor que coze o cuscuz? Por que o cuscuz fazia parte do cozido à madeirense? Nas localidades onde ainda se faz e coze cuscuz, usando o chamado cuscuzeiro ou cuscuzeira (feito de barro ou alumínio, com furos no fundo, que se coloca sobre uma panela ao lume com água, para cozer o "triguilho" a vapor), não se confundem? Hoje, o cuscuz é característico da zona oeste da Madeira

\footnotetext{
${ }^{67}$ Cruz 1963: 43.

${ }^{68}$ Cardoso 1994: 134.
} 
(da Ponta do Sol a S. Vicente), mas Sousa mostra que a tradição de fazer e cozinhar cuscuz não era desconhecida na parte leste da ilha.

O cuscuz constava do receituário tradicional das cozinhas dos solares da Vila de Machico. De acordo com a tradição oral, era costume as casas abastadas contratarem uma pessoa especializada na confeção desta receita. Normalmente era um prato confecionado em dezembro, antecedendo a matança do porco. (...) um interessante exemplar da olaria madeirense dos finais do século XVIII encontra-se no Núcleo Museológico de Machico. ${ }^{69}$

Tal como em Cabo Verde, na Madeira, o cuscuz foi alimento de pobres e ricos, neste caso acompanhado de carne. A Revista Folclore informa que o cuscuz de trigo na alimentação tradicional madeirense de S. Vicente era utilizado todo o ano, principalmente entre novembro e junho, porque se cozinha com linguiça de porco e esta era feita com a matança do porco para a Festa. Acrescenta que "O cuscuz é cozido na panela com banha de porco e alho, linguiça, ovos e segurelha. Pode ser frito." ${ }^{\circ}$. Nos Açores, o cuscuz é uma "iguaria de Santa Maria", ilha que mais elementos mouriscos recebeu aquando do povoamento dos Açores, consistindo em "pequenas bolinhas de farinha de trigo cozidas em vapor de água e depois postas ao sol a secar (do ár. Kuskus).”. O cuscuzeiro é o recipiente de barro com o fundo perfurado para cozer o cuscuz a vapor e o cuscuz serve "como substituto do arroz ou da massa"' 71 . No Brasil, Freyre, a propósito do cuscuz, escreve: "O cuscuz dos árabes, por exemplo, o alfenim, a alféloa ou felô, os filhós ou filhoses e muita coisa que hoje nos parece brasileira que nem doce de caju é portuguesa da Silva e do tempo dos Afonsinhos.". Mais à frente afirma: “Um costume conservado de Lisboa do século XVI foi o de negras com panelas, balaios e tabuleiros de doce, que saíam pelas ruas do Rio, da Bahia, do Recife apregoando sua alféloa, seu alfenim, seu doce. Também o de venderem o seu cuscuz ou seu arroz-doce.". Conclui que a tradição vinda de Portugal foi se mantendo "de muito quitute mourisco ou africano: o alfenim, a alféloa, o cuscuz, conservados nos tabuleiros ao lado dos brasileirismos como as cocadas" ${ }^{72}$.

Além dos doces resultantes do mel de cana e do açúcar, o sumo da cana-de-açúcar fermentado permite o fabrico de aguardente de cana, cachaça no Brasil, enquanto em Cabo Verde esta bebida é designada grogue (grogu ou grog'). Dada a diminuta produção de grogue, face à procura, este é adulterado, sendo

\footnotetext{
${ }^{69}$ Sousa 2011: 337.

${ }^{70}$ Folclore 1998: 31.

${ }^{71}$ Barcelos 2008: 201.

${ }^{72}$ Freyre 1997: 57, 84 e 176.
} 
feito a partir de açúcar. Tal como na Madeira, também se prepara grogue com ervas aromáticas ou medicinais. Em Cabo Verde, muitos informantes relatam que se faz "grogo com sangue de draga", ou seja, mistura-se a aguardente com a seiva de dragoeiro. No Porto Santo, parece que também era comum tomar um cálice de bebida semelhante para tirar dores. Na ilha de Santo Antão, é feita uma bebida à base de grogue, denominada pontche, que inclui limão e açúcar, podendo levar também canela. Quando é feita com mel de cana, em vez de açúcar, é chamada ponche de mel (pontche de mel), existindo também a ponche de coco e de madeiro. Esta bebida pela sua denominação e composição aproxima-se da poncha madeirense. Em Receitas com mel-de-cana, encontramos uma receita inovadora de poncha com mel-de-cana, em que se mistura o mel-de-cana com o sumo do limão, mexendo muito bem com um "mexilote" ou pau da poncha. Depois junta-se a aguardente e volta-se a misturar bem ${ }^{73}$. Esta "poncha de mel-de-cana" da Madeira aproxima-se da ponche de Cabo Verde. Na Madeira, a mistura de aguardente com mel-de-cana chama-se macia. Pode ser simples ou com canela, casca de laranja e folha de louro ou outros ingredientes. Figueira também regista uma bebida denominada aguardente de mel, com mel de abelhas e erva-doce ${ }^{74}$, porém sabemos que esta também é feita com mel de cana. No Nordeste do Brasil, Freyre refere como bebidas regionais mais características, entre outras, o cachimbo (mel com cachaça), o bate-bate (maracujá com cachaça) e a pitangada (pitanga com cachaça) ${ }^{75}$. Estas últimas lembram-nos a poncha madeirense, que hoje também é feita com maracujá e outras frutas.

$\mathrm{Na}$ ilha da Madeira, também encontramos a ocorrência da palavra grogue (do inglês grog), assim como da palavra derivada grogada. Em Canhas e Câmara de Lobos, Estudo etnográfico e linguístico, grogue é sinónimo de 'aguardente de cana-de-açúcar (copo pequeno)' e grogada também é 'aguardente" ${ }^{76}$. Silva, no Vocabulário Popular da Madeira, define grogada "(do ing1. grog) aguardente" e grogue "pequeno copo dessa bebida, equivalente a 0,07 1." 77 . Pestana regista grogue como "um cálice de aguardente" e a palavra snap como "meio 'grog', também usado no diminutivo snapzinho"78. Os dicionários de Língua Portuguesa não registam a forma grogada que, na Madeira, parece ser sinónimo de aguardente. $\mathrm{Na}$ ilha da Madeira, nos meios rurais, toma-se um grogue de manhã em jejum, para aquecer e evitar as gripes, principalmente

\footnotetext{
${ }^{73}$ Freitas 2008.

${ }^{74}$ Figueira 1993: 139.

${ }^{75}$ Freyre 1997: 38.

${ }^{76}$ Rezende 1961: 291.

${ }^{77}$ Silva 1950: 69.

${ }^{78}$ Pestana 1970: 82 e 117.
} 
dos pescadores e agricultores que se levantam cedo com o frio, chamando-se "tomar um grogue" ou "meio grogue".

Em S. Tomé e Príncipe, além do nome grogue, a aguardente de cana também é denominada cacharamba (do crioulo forro kaxaramba), sobretudo quando é de inferior qualidade, feita com açúcar e não com o sumo da cana, significando também 'bebedeira'. Neste arquipélago, o cultivo da cana é usado principalmente para o fabrico de aguardente, havendo um grande problema de alcoolismo e doenças mentais na população, devido à aguardente adulterada com açúcar, muito mais prejudicial à saúde. Além da aguardente de cana, grogue ou cachaça do Brasil, em todas estas áreas açucareiras, incluindo os Açores, existem também os licores de várias frutas, ervas aromáticas e essências, que resultam principalmente da existência da produção da aguardente de cana, embora se utilize cada vez mais o álcool, por ser mais barato, mas com prejuízos para a saúde.

O desenvolvimento das relações comerciais e culturais entre as ilhas atlânticas e o Brasil deveu-se sobretudo à produção açucareira. O estudo da cultura açucareira, associada aos doces e bebidas tradicionais ou populares da Madeira, das Canárias, de Cabo Verde, de S. Tomé e do Brasil, aparentemente manifestações culturais ilhadas, mostra-nos um património atlântico comum, herança das inter-relações históricas entre línguas e culturas. Como afirma Sainz-Trueva: "Doces e sabores com gosto a Oriente, África, Brasil, Canárias. Simbiose de paladares de gente que ora se dispersava ora voltava à ilha para aqui deixar novos hábitos e comidas." 79 . As ilhas atlânticas e o Brasil participaram nesta circulação de coisas e palavras, formando o nosso património alimentar comum, os sabores e saberes da tradição que marca a nossa memória coletiva.

\section{REFERENCIAS BIBLIOGRÁFICAS}

Antonil, A. J. (1711), Cultura e opulencia do Brasil por suas drogas e minas, edição facsimilada, Imprensa Nacional, Lisboa.

Aulete, F. J. C. (1881), Dicionário contemporâneo da lingua portuguesa, 2 vols., Imprensa Nacional, Lisboa.

Barros, A. L. de (2013), As receitas de cozinha de um frade Português do século XVI, Coimbra, Imprensa da Universidade de Coimbra.

Bluteau, R. (1712-1721), Vocabulario Portuguez e Latino (autorizado com exemplos dos melhores escritores portuguezes e latinos e oferecido a el rey de Portugal D. João V), 10 vols., Colégio das Artes da Companhia de Jesus, Coimbra.

Braga, I. M. R. M. D. (2014), “Confeitos na Época Moderna: cultura material, produção e conflituosidade", in C. Soares e I. C. Macedo (eds.) Ensaios sobre património

\footnotetext{
${ }^{79}$ Sainz-Trueva 1987: 32-33.
} 
alimentar luso-brasileiro, Imprensa da Universidade de Coimbra, Annablume Editora, Coimbra, pp. 165-192.

Branco, F. F. (1995), Porto Santo: registos insulares, Edição do Autor, Porto Santo.

Cardoso, Z. (1987), Machico na gastronomia, Edição da Câmara Municipal de Machico e da DRAC, Funchal.

Cardoso, Z. (1994, 2a edição), Segredos de cozinha. Madeira e Porto Santo, Edição da Autora, Machico.

Cascudo, L. da C. (1985, 10ª edição), Dicionário do Folclore Brasileiro, Coleção Terra Brasilis, Ediouro, Rio de Janeiro.

Cruz, V. do P. da (1963), “A culinária madeirense”, Das Artes e da História da Madeira, no 33, Funchal, pp. 42-47.

Ferreira, A. B. de H. (1999, 3a edição), Novo Aurélio Século XXI. O Dicionário da língua portuguesa, Editora Nova Fronteira, Rio de Janeiro.

Figueira, A. I. (1993), Cozinha Regional da Madeira, Publicações Europa-América, Lisboa.

Figueira, A. I. (coord.) (1997, 4a edição), Cozinha madeirense, Secretaria Regional de Educação, Governo Regional da Madeira.

Figueiredo, C. de (1899), Novo Dicionário da Lingua Portuguesa, 2 vols., Livraria Editora Tavares Cardoso, Lisboa.

Filho, J. L. (1997), O corpo e o pão. O vestuário e o regime alimentar cabo-verdianos, Câmara Municipal de Oeiras, Oeiras.

Folclore, 1998, Secretaria Regional de Agricultura, Florestas e Pescas, Governo Regional da Madeira.

Freyre, G. (1997), Açúcar. Uma sociologia do doce, com receitas de bolos e doces do Nordeste do Brasil, Companhia das Letras, São Paulo.

Freitas, O. (2008), Receitas com mel-de-cana, Fábrica do Ribeiro Seco, Funchal.

Frutuoso, G. (1977-1987), Saudades da Terra, 6 livros, Instituto Cultural de Ponta Delgada, Ponta Delgada [várias edições].

Gastronomia tradicional da Madeira e Porto Santo (2013), Região Autónoma da Madeira, DRAC, Funchal.

Gomes, A. (1982), Cozinha tradicional da ilha Terceira, Angra do Heroísmo, DRACGoverno Regional dos Açores.

Gomes, A. (1987, 2a edição), Cozinha tradicional da ilha de S. Miguel, DRAC-Governo Regional dos Açores, Angra do Heroísmo.

Houaiss, A. e VILLAR, M. de S. (2001), Dicionário Houaiss da língua portuguesa (elaborado pelo Instituto Antônio Houaiss de Lexicografia e Banco de Dados da Língua Portuguesa S/C Ltda), Objetiva, Rio de Janeiro.

Macedo, J. C. (2014), “Aspectos culturais na prática do aleitamento materno decorrentes da herança histórica do Brasil Colónia”, in C. Soares e J. Macedo (eds), Ensaios sobre património alimentar luso-brasileiro, Imprensa da Universidade de Coimbra, Annablume Editora, p. 275-326. 
Mel de cana sacarina produzido na Região Autónoma da Madeira: seus benefícios no corpo bumano, modos de utilização, elemento preponderante na doçaria madeirense, edição de V. Melim, Lda., Fábrica do Ribeiro Seco, Funchal, s.d.

Melo, L. F. C. de S. (1972-1990), “Tombo primeiro do registo geral da Câmara Municipal do Funchal”, Arquivo Histórico da Madeira (XV-XIX), 5 vols., DRAC, Funchal.

Morais Silva, A. de (1813, 2a edição), Diccionário da Lingua Portugueza (recopilado dos vocabulários impressos ate agora e nesta segunda edição novamente emendado e muito acrescentado), 2 vols, Typographia Lacerdina, Lisboa.

Morera, M. (1992), “Termos canários na Madeira”, Xarabanda Revista 2, Associação Musical e Cultural Xarabanda, Funchal: 10-12.

Memórias com história, 2012, Secretaria Regional de Educação e Recursos Humanos, Região Autónoma da Madeira.

Nunes, N. N. (2001), "A terminologia histórica do açúcar nas ilhas atlânticas: Madeira e Canárias (séculos XV e XVI), Les îles Atlantiques: realités et imaginaire, Université Rennes 2, Rennes, 139-161.

Nunes, N. N. (2003), Palavras doces. Terminologia e tecnologia históricas e atuais da cultura açucareira: do Mediterrâneo ao Atlântico, Centro de Estudos de História do Atlântico, Governo Regional da Madeira.

Nunes, N. N. (2010), Outras palavras doces. Glossário comparativo da atual terminologia açucareira no Atlântico, Secretaria Regional de Educação e Cultura, Centro de Estudos de História do Atlântico, Região Autónoma da Madeira.

Pérez Vidal, J. (1947), "Conservas y dulces de Canarias", Revista de Dialectologia y Tradiciones Populares III: 236-248.

Pérez Vidal,J. (1981), “Canarias, el azúcar, los dulces y las conservas”, Jornadas de Estudios Canarias - América, Servicio de Publicaciones de la Caja General de Ahorros y Monte de Piedad de Santa Cruz de Tenerife, Santa Cruz de Tenerife, 173-193.

Pérez Vidal,J. (1983), “La rapadura”,El Museo Canario (Revista publicada por la sociedad del mismo nombre de Las Palmas de Gran Canaria) XLIII: 55-68.

Pérez Vidal, J. (1991), Los portugueses en Canarias. Portuguesismos, Ediciones del Cabildo de Gran Canaria, Las Palmas de Gran Canaria.

Pestana, E. (1970), Ilha da Madeira, 2 vols, Câmara Municipal do Funchal, Funchal.

Rabelo, S. (1969), Cana-de-açúcar e região. Aspectos sócio-culturais dos engenhos de rapadura nordestinos, Instituto Joaquim Nabuco de Pesquisas Sociais - MEC, Recife.

Rebelo, H. (2014), "Património linguístico madeirense. Alguns aspectos lexicais, fonéticos, morfológicos e sintácticos”, La Lengua Portuguesa, vol. II, Estudios Linguísticos, Ediciones Universidad de Salamanca, Salamanca.

Rezende, M. A. L. (1961), Canhas e Câmara de Lobos: estudo etnográfico e linguístico, dissertação de Licenciatura em Filologia Românica, apresentada à Faculdade de Letras da Universidade de Lisboa, Lisboa.

Ribeiro,J.A. (1993), “A casquinha na rota das navegações do Atlântico Norte nos séculos XVI-XVII”, Actas III Colóquio Internacional de História da Madeira, Separata, Centro de Estudos de História do Atlântico, Secretaria Regional do Turismo e Cultura, Funchal. 
Sainz-Trueva, J. (1987), "Doces e sabores do quotidiano madeirense”, Cousas E̋ Lousas das Cozinhas Madeirenses (Catálogo de exposição, Teatro Municipal, dezembro de 1987/janeiro de 1988), Governo Regional da Madeira, Secretaria Regional do Turismo e Cultura, DRAC, Editorial Eco do Funchal, Funchal, 13-33.

Sarmento, T.-C. (1941), As pequenas indústrias da Madeira, Diário de Notícias, Funchal.

Silva, F. A. (1950), Vocabulário Popular da Madeira, Junta Geral do Distrito Autónomo do Funchal, Funchal.

Sousa, A. M. de (1948), "O bolo de mel das freiras da Encarnação”, Das Artes e da História da Madeira (suplemento ao no 4927 de "O Jornal”), Funchal, 51-52.

Sousa, E. (2012), “A doçaria madeirense”, Sabores e saberes da doçaria portuguesa, Instituto de Emprego e Formação Profissional, Lisboa, 93-105.

Sousa, J.J. A. de (2008), O bolo de mel. Ex libris da doçaria madeirense, Associação Cultural Memórias Gastronómicas, Funchal.

Veríssimo, N. (1987), “À mesa no século XVIII”, Cousas E̊ lousas das cozinhas madeirenses (Catálogo de exposição, Teatro Municipal, dezembro de 1987/janeiro de 1988), Governo Regional da Madeira, Secretaria Regional do Turismo e Cultura, DRAC, Funchal, Editorial Eco do Funchal, 35-47.

Vieira, Fr. D. (1871-1874), Grande Diccionario Portuguez ou Thesouro da Lingua Portugueza, 5 vols, Editores Ernesto Chardron e Bartholomeu Moraes, Porto.

\section{Webgrafia}

"O gófio da Ti Joaquina” in O_rabo_do_gato. Disponível em: http://o-rabo-do-gato. blogspot.pt/2010/08/o-gofio-da-ti-joaquina.html (consultado a 23 de junho de 2015). 